ENVIRONMENTAL ASSESSMENT

\title{
Assessing Impacts of Typhoons and the Chi-Chi Earthquake on Chenyulan Watershed Landscape Pattern in Central Taiwan Using Landscape Metrics
}

\author{
YU-PIN LIN* \\ TSUN-KUO CHANG \\ Department of Bioenvironmental Systems Engineering \\ National Taiwan University \\ 1 Sec. 4 Roosevelt Rd. \\ Taipei 106, Taiwan
}

\section{CHEN-FA WU}

Graduate Institute of Urban Planning

National Taipei University

69 Sec. 2 Chien Kwo Rd.

Taipei 104, Taiwan

\section{TE-CHIH CHIANG}

Department of Geography

Chinese Culture University

55 Hwa-Ken Rd.

Yangming Shan

Taipei 111, Taiwan

\section{SHIN-HWEI LIN}

Department of Soil and Water Conservation

National Chung Hsing University

250 Kuo Kuanfg Rd.

Taichung City 402, Taiwan

ABSTRACT / The Chi-Chi earthquake ( $M_{L}=7.3$ ) occurred in the central part of Taiwan on September 21, 1999. After the earthquake, typhoons Xangsane and Toraji produced heavy rainfall that fell across the eastern and central parts of Taiwan on November 2000 and July 2001. This study uses remote sensing data, landscape metrics, multivariate statistical analysis, and spatial autocorrelation to assess how earthquake and typhoons affect landscape patterns. It addresses variations of the Chenyulan watershed in Nantou County, near the earthquake's epicenter and crossed by Typhoon Toraji. The subsequent disturbances have gradually changed landscape of the Chenyulan watershed. Disturbances of various types, sizes, and intensities, following various tracks, have various effects on the landscape patterns and variations of the Chenyulan watershed. The landscape metrics that are obtained by multivariate statistical analyses showed that the disturbances produced variously fragmented patches, interspersed with other patches and isolated from patches of the same type across the entire Chenyulan watershed. The disturbances also affected the isolation, size, and shapecomplexity of patches at the landscape and class levels. The disturbances at the class level more strongly affected spatial variations in the landscape as well as patterns of grasslands and bare land, than variations in the watershed farmland and forest. Moreover, the earthquake with high magnitude was a starter to create these landscape variations in space in the Chenyulan watershed. The cumulative impacts of the disturbances on the watershed landscape pattern had existed, especially landslides and grassland in the study area, but were not always evident in space and time in landscape and other class levels.
Physical disturbances, such as fires, hurricanes, tornadoes, typhoons, landslides, and earthquakes, are characterized by a large amount of energy change and may arrive from various directions and in various forms (Forman 1995). These widespread natural phenomena may be defined as discrete events in time that change landscapes, ecosystems, communities, and population

KEY WORDS: Landscape pattern; Landscape metrics; Chi-Chi earthquake; Typhoon; Disturbance impact; Watershed; Taiwan

Published online April 21, 2006

*Author to whom correspondence should be addressed; email: yplin@ntu.edu.tw structures, affecting the substrate, the physical environment, and the availability of resources (White and Pickett 1985). The width of a disturbance almost always changes as the disturbance moves, leaving a distinctive squiggly bordered signature on the land (Forman 1995), but sometimes it does not significantly influence the landscape. For example, when hurricanes strike a mountainous landscape, the wind intensity, the precipitation, and the subsequent storm damage vary across it, and landslides may occur in some areas (Lugo and Waide 1993; Boose and others 1994; Turner and others 1998). Moreover, hurricanes, tornadoes and downbursts exhibit extreme gradients of size and severity of wind damage; however, all storms have gra- 
dients of intensity and severities, and cause damage to various spatial extents (Foster and others 1998; Turner and others 2001). Landslides are susceptible to being triggered by the combined effects of steep topography, weak geological formations, typhoons with torrential rainfall, and earthquakes. Earthquakes, shaking the ground, can trigger all types of landslide, all of which can therefore occur without seismic triggering (Jibson 1996). Therefore, these disturbances may dominate the creation of a complex landscape or cause a certain change to the land surface in disturbed regimes. However, understanding the impacts of the disturbance on the landscape patterns is an essential task for managing or restoring the disturbed area.

Landscape pattern refers to the number, size, and juxtaposition of landscape elements or patches, which are important contributors to overall landscape pattern and interpret action of the ecological processes (Gardner and others 1987; O’Neill and others 1988). Landscape indices reflect "cross-cutting" interaction between ecosystems, either directly through energy flow measures, nutrients, or hydrology, or through the biological conditions of a subsystem that serves as a sentinel for larger landscape conditions (Raport and others 1998). These metrics may include area, shape, edge, nearest neighbor, diversity, interspersion, and contagion metrics. For example, the disturbance regimes can be measured using various indices, e.g., degree of fragmentation, fractal dimension, contagion, juxtaposition, evenness, and patchiness ( $\mathrm{Li}$ and Reynolds 1994). There are numerous landscape ecological reports that use landscape indices and discuss the use of indices. Typical examples include Obeysekera and Rutchey (1997), Collins and Barrett (1997), Gustafson (1998), Aguiar and Sala (1999), Hokit and others (1999), Cushman and Wallin (2000), Weinstoerffer and Girardin (2000), Lausch and Herzog (2002), Remmel and Csillag (2003), and $\mathrm{Li}$ and Wu (2004). More recently, landscape ecological research using landscape indices in natural disturbance studies includes wildfires (Moreira and others 2001; Hansen and others 2001; Hudak and others 2004), wildfires and insects (Hessburg and others 2000), deforestation (Fitzsimmons 2003; Venema and others 2005), and ice storms (Faccio 2003).

Current studies of land use/cover change and landscape fragmentation rely on land cover classifications derived from remotely sensed images in GIS. Liu and others (2003) examined the landscape dynamics at a watershed scale using Landsat TM imagery with landscape indices for the discovery of wintering Hooded Crane Decline in Yashiro, Japan. Tinker and others (2003) used GIS and landscape metrics to evaluate landscape patterns of the Rocky Mountain's coniferous forest that have been subjected to intensive timber harvest. Baldwin and others (2004) tested the suite landscape pattern indices' sensitivity, which is useful for disturbance emulation strategy development and evaluation of spatial extent, spatial resolution, and thematic resolution using land cover data for a managed forest case study in Ontario, Canada. Cifaldi and others (2004) used landscape metrics to quantify spatial patterns and gradients of land cover variation of exurbanizing southeastern Michigan's watersheds. Zhang and others (2004) used remote sensing images with landscape metrics to quantify landscape patterns and its gradients of the Shanghai metropolitan area, China.

More information on multiple-metrics could provide insight into landscape patterns in time and space. Multivariate statistics provided a measure of figuring out multiple-metrics, such as factor analysis and principal components analysis (Cifaldi and others 2004; Hudak and others 2004; Venema and others 2005). A small set of uncorrelated metrics is much easier to understand and use in further analysis than a larger set of correlated landscape metrics. Each factor containing a number of landscape indices may present the landscape pattern's characters. Such typical studies of using landscape metrics with multivariate analysis include Riitters and others (1995), Cain and others (1997), Tinker and others (1998), Cushman and Wallin (2000), Griffith and others (2000), Johnson and others (2001), Cumming and Vernier (2002), Lausch and Herzog (2002), Lin and others (2002), Honnay and others (2003), Cifaldi and others (2004), and Hudak and others (2004).

Spatial autocorrelation is a useful tool for analyzing spatial patterns of values. Spatial structures are first described by so-called structure functions (Legendre 1993). One of the spatial autocorrelation methods is Moran's I correlogram. Moran's I ranges between -1 and +1 . Moran's $\mathrm{I}$ is high and positive when one value is similar to adjacent values. A low Moran's I value is dissimilar to adjacent values. A correlogram is a graph in which autocorrelation values are plotted on the ordinate against distance classes among localities on the abscissa (Legendre 1993). Therefore, Moran's I correlogram has been widely used to analyze spatial patterns associated with ecological phenomena.

Taiwan has a subtropical environment. It is located on the Philippine plate and at the Euro-Asian Plate junction (DeMets and others 1990). Disastrous earthquakes occasionally affect Taiwan because of the plate convergence and typhoons. In this study, remote sensing data, landscape metrics, one-way ANOVA, 


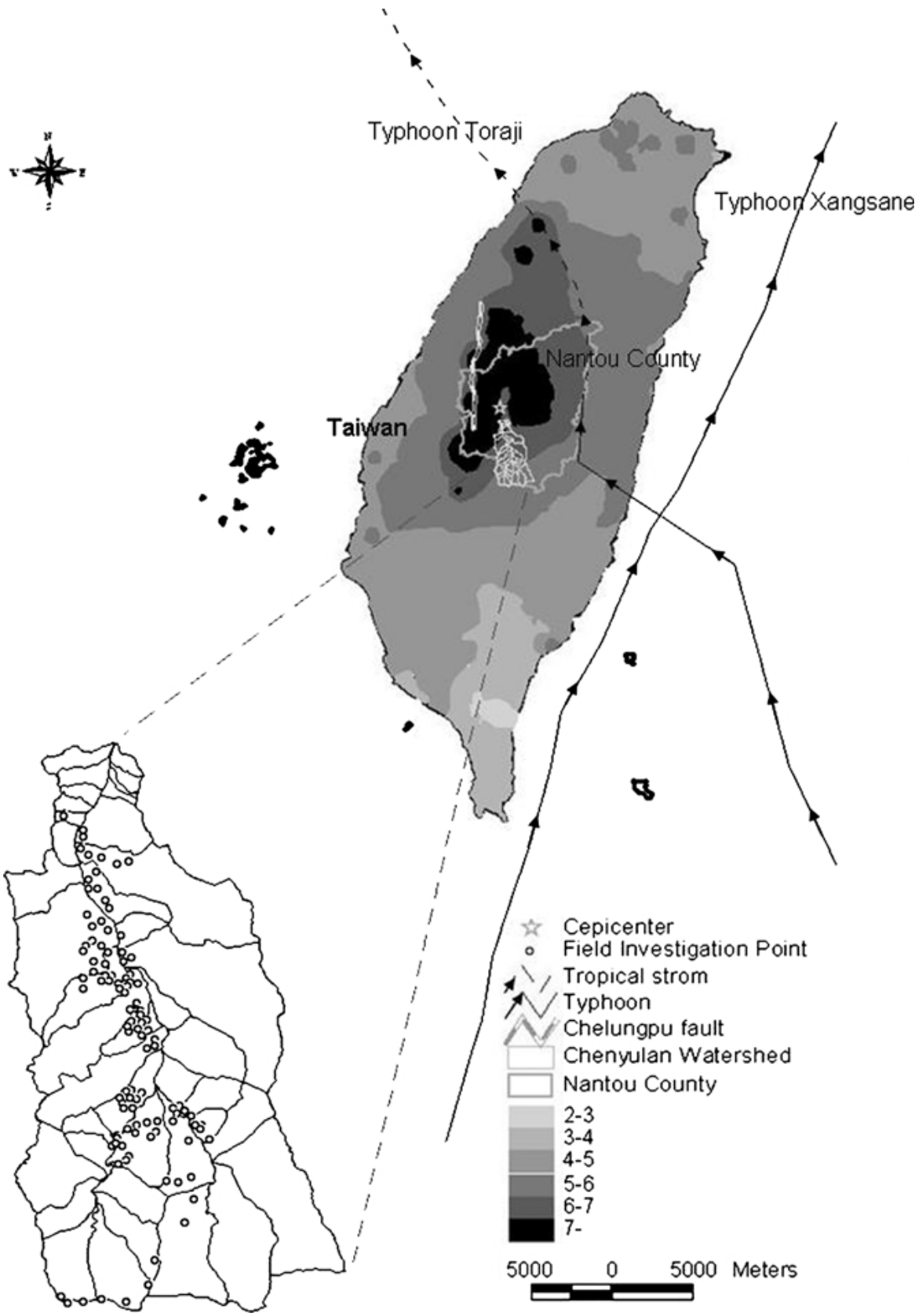

Figure 1. Disturbances and study area.

factor analysis, and spatial autocorrelation are used to assess the impact of the Chi-Chi earthquake and Xiangsane and Toraji typhoons on landscape patterns of the Chenyulan watersheds in the southern part of Nantou County near the earthquake's epicenter (Figure 1). Landscape metrics are applied to delineate the changes in the spatial patterns of the landscape caused by the earthquake and typhoons. Oneway ANOVA is used to compare differences among landscape metrics of the watershed and sub-watersheds over various periods, to test the hypothesis that the disturbances affect the landscape and class levels of the watershed. Factor analysis and landscape indices of Chenyulan watershed's sub-watersheds are used to characterize the factor patterns represented by a few sets of landscape metrics. Moreover, factor scores of sub-watersheds in each period of disturbance are input into GS+ (Gamma Design 1995) to calculate the spatial autocorrelations and generate Moran's I correlograms to delineate the spatial variations of each factor in the landscape and the class levels before and after the disturbances, and to compare the spatial 
variations in the landscape of the sub-watershed before and after the disturbances.

\section{Materials and Methods}

\section{Study Area and Disturbances}

The Chenyulan watershed has an area of $449 \mathrm{~km}^{2}$ and is located in central Taiwan's Nantou County (Figure 1). The Chenyulan watershed is a typical mountainous drainage watershed elongated in a northsouth direction with a mean altitude of $1540 \mathrm{~m}$, a slope of $32^{\circ}$, and relief of $585 \mathrm{~m} / \mathrm{km}$. The gradient of the main course is $6.1 \%$ and more than $60 \%$ of its tributaries have gradients that are steeper than 20\% (Chang 1997). Slates and meta-sandstones are the dominant lithologies in the metamorphic terrains (Lin and others 2003). Based on the relative amounts of slate and meta-sandstone, the metamorphic strata in the eastern part of the study area are divided into four parts: Shihpachuangchi, Tachien Meta-Sandstone, Paileng MetaSandstone, and Shuichangliu (Lin and others 2003). In this study, the watershed was divided into 41 subwatersheds with an average area of $10.93 \mathrm{~km}^{2}$ and an average elevation of $1306.52 \mathrm{~m}$ (590.00-2436.61 m) (Figure 1).

The September 21, 1999, Chi-Chi earthquake occurred at 1:47 a.m. local time (17:47:18 GMT the previous day) at an epicentral location of $23.85^{\circ} \mathrm{N}$ and $120.78^{\circ} \mathrm{E}$ and at a depth $6.99 \mathrm{~km}$ (Figure 1). It was caused by a rupture in the Chelungpu Fault. The magnitude of the earthquake was estimated to be $\mathrm{M}_{\mathrm{L}}=7.3\left(\mathrm{M}_{\mathrm{L}}\right.$ : Local Magnitude or Richter Magnitude), and the rupture zone, defined by the aftershocks, measured about $80 \mathrm{~km}$ north-south by 25-30 km downdip (Roger and Yu 2000). Iso-contour maps of the earthquake's magnitude were reproduced from the Central Weather Bureau (Figure 1) (CWB 1999). The earthquake caused surface ruptures along approximately $100 \mathrm{~km}$ in a north-south direction of the Chelungpu fault. It caused 10,000 landslides and severely altered the landscape patterns around the center of Taiwan, especially in the area near the earthquake's epicenter.

After the earthquake, from October 31, 2000 to November 1, 2000, the center of typhoon Xiangsane moved from south to north through eastern Taiwan (CWB 2000), with a maximum wind speed of $138.9 \mathrm{~km} / \mathrm{hr}$ and a radius of $250 \mathrm{~km}$, with gusts of $166.7 \mathrm{~km} / \mathrm{hr}$ (Figure 1). The maximum daily rainfall was $550 \mathrm{~mm} /$ day. On July 30, 2001, the Toraji typhoon swept across central Taiwan from east to west (CWB 2001), with a maximum wind speed of $138.9 \mathrm{~km} / \mathrm{hr}$ and a radius of $180 \mathrm{~km}$ (Figure 1). The typhoon brought extremely heavy rainfall, from 230 to $650 \mathrm{~mm} /$ day, and triggered more than 6000 landslides in Taiwan. The recent Typhoon Toraji had the most intense rainfall over a short period, with the return period of 300 years (Cheng and others 2005). These typhoons brought torrential rainfall, which washed away the soil that had already been loosened by the Chi-Chi earthquake, causing major landslides and debris flows, and even changes in the landscape in central Taiwan.

\section{Landscape Images and Classification}

Cloud-free SPOT images were used to classify the watershed landscapes on March 6, 1999, October 21, 1999, November 27, 2000, and September 21, 2001 before and after the earthquake and typhoons. The SPOT images were first classified by using supervised classification with maximum likelihood and fuzzy methods. Supervised classification and fuzzy convolution are performed using the software ERDAS IMAGINE with $1 / 5000$ black and white aerial photographs and ground truth data. Each class is marked on the aerial photographs by the Aerial Survey Office, Forestry Bureau in Taiwan. Moreover, ground truth data were obtained by using a Global Position System (GPS) before the classifications of images. The classified images and information on roads, buildings, slopes, and band ranges of the watersheds were used with the Knowledge Engineer component of IMAGINE to determine the final classification of the SPOT images. In this study, the six land cover categories were forest, grassland, farmland, water, bare land, and buildup. Bare land included landslides. A total of 756 pixels were used to evaluate the final accuracy of each SPOT image. Moreover, 109 field sampling points of 756 ground truth points were investigated within the watershed in 2003 (Figure 1). Between 30 and 475 accuracy assessment sites were used per training class. Table 1 lists the total accuracy, the average producer's accuracy, the average consumer's accuracy, and the kappa values of the classifications of the images for each year. All overall accuracy and Kappa values are greater than $90.0 \%$ and 0.8 , respectively. The average producer's accuracy and user's accuracy exceed $82.4 \%$ and $91.3 \%$, respectively. The user's accuracies, from $83.3 \%$ to $100 \%$, for all individual classes in all years were acceptable. The producer's accuracies of classifications, ranging from $83.2 \%$ to $100 \%$, for all individual classes in all years, with the exception of grassland, were acceptable. Although the user's accuracies for grassland class ranged from $83.3 \%$ to $89.9 \%$, the producer's accuracies ranged from only $39.5 \%$ to $42.9 \%$. This range may result in uncertainty in the landscape pattern analyses of grassland. 
Table 1. Images classification results

\begin{tabular}{|c|c|c|c|c|c|}
\hline Date & Class & $\begin{array}{c}\text { Producer's } \\
\text { accuracy (\%) }\end{array}$ & $\begin{array}{c}\text { Consumer's } \\
\text { accuracy (\%) }\end{array}$ & $\begin{array}{c}\text { Overall } \\
\text { accuracy }(\%)\end{array}$ & Kappa \\
\hline \multirow[t]{6}{*}{ 03/06/1999 } & Buildup & 96.77 & 93.75 & \multirow{6}{*}{94.3} & \multirow{6}{*}{0.847} \\
\hline & Forest & 97.78 & 93.08 & & \\
\hline & Grassland & 41.03 & 88.89 & & \\
\hline & Farmland & 85.82 & 87.79 & & \\
\hline & Bare land & 93.75 & 97.83 & & \\
\hline & Average & 83.03 & 92.27 & & \\
\hline \multirow[t]{6}{*}{$31 / 10 / 1999$} & Buildup & 96.77 & 93.75 & \multirow{6}{*}{94.1} & \multirow{6}{*}{0.845} \\
\hline & Forest & 97.97 & 92.88 & & \\
\hline & Grassland & 42.86 & 83.33 & & \\
\hline & Farmland & 83.45 & 88.55 & & \\
\hline & Bare land & 91.84 & 97.83 & & \\
\hline & Average & 82.58 & 91.27 & & \\
\hline \multirow[t]{6}{*}{$27 / 11 / 2000$} & Buildup & 96.77 & 93.75 & \multirow{6}{*}{94.3} & \multirow{6}{*}{0.849} \\
\hline & Forest & 98.57 & 92.50 & & \\
\hline & Grassland & 41.67 & 83.33 & & \\
\hline & Farmland & 83.22 & 90.84 & & \\
\hline & Bare land & 91.84 & 97.83 & & \\
\hline & Average & 82.41 & 91.65 & & \\
\hline \multirow[t]{6}{*}{$20 / 11 / 2001$} & Buildup & 100.00 & 93.75 & \multirow{6}{*}{95.1} & \multirow{6}{*}{0.865} \\
\hline & Forest & 98.37 & 93.98 & & \\
\hline & Grassland & 39.47 & 83.33 & & \\
\hline & Farmland & 86.67 & 88.64 & & \\
\hline & Bare land & 96.15 & 100.00 & & \\
\hline & Average & 84.13 & 91.94 & & \\
\hline
\end{tabular}

\section{Landscape Metrics}

An attempt was made to assess how the earthquake and typhoons affected the landscape patterns and changes of the studied watersheds at both landscape and class levels by calculating the landscape metrics of each watershed classified images using patch analysis (McGarigal and Marks 1995) in the GIS software package Arcview 3.0a. At the class level, buildup and water were not considered in landscape change analysis, because of slight changes in assumptions on buildup and water patches. Landscape indices and their equations were introduced in more detailed landscape metrics in the user's menu of FRAGSTATS (McGarigal and Marks 1995). Number of Patches (NP), Total Edge (TE), Mean Patch Size (MPS), Standard Deviation of Patch Size (PSSD), Mean Shape Index (MSI), Mean Patch Fractal Dimension (MPFD), Mean Proximity Index (MPI), and Interspersion and Juxtaposition Index (IIJ) are used in this study because disturbance-induced changes sometimes affect patch size, edge, fractal, shape, and interspersion.

Number of Patches of a particular habitat type may affect a range of ecological processes, depending on the landscape context. Mean Patch Size and Patch Size of Standard Deviation are used to account for variation in patch size for both landscape and class levels. Mean Shape Index measures the average patch shape, or the average perimeter-to-area ratio, for a particular patch type or for all patches in the landscape and class. When all patches in the landscape are squares, Mean Shape Index $=1$. It increases limitlessly as the patch shapes become more irregular. Mean Patch Fractal Dimension approaches a value of one for shapes with very simple perimeters, such as circles or squares, and approaches two for shapes with highly complicated, plane-filling perimeters. Mean Proximity index is zero if no patch has a neighbor of the same type within the specified search radius. Moreover, Mean Proximity index increases as patches become less isolated from patches of the same type and their types become less fragmented in distribution. Interspersion and Juxtaposition Index approaches zero when the distribution of adjacencies among unique patch types becomes increasingly uneven. Interspersion and Juxtaposition Index is 100 when all patch types are equally adjacent to all other patch types. These metrics quantify fundamental aspects of landscape composition and configuration (McGarigal and Marks 1995), which are useful to describe landscape structure in real landscape (Riitters and others 1995).

\section{Statistical Analysis}

One-way dependent samples ANOVA yields the differences among the landscape metrics of sub-watershed landscapes during various disturbances, to test 
the hypotheses that disturbances change landscape patterns. In this study, the multi-temporal factor analysis with principal component methods (Marshall and Elliott 1997; Cushman and Wallin 2000; Hudak and others 2004) in the statistical software SPSS (Norusis 1993) was performed by computing the eigenvalues and eigenvectors of the landscape metrics of 41 subwatersheds to group and delineating the spatial changes of watershed landscape patterns before and after the disturbances. Factors with the eigenvalues higher than one were retained. Finally, the factor scores were calculated from the landscape indices, using regression methods with a matrix of factor-score coefficients. The factor scores were input into GS+ (Gamma Design $1995)$ to calculate and perform Moran's I correlogram with a lag distance interval of $2000 \mathrm{~m}$. Then, spatial autocorrelation (Moran's I) of factor scores was used to delineate spatial variations in the landscape and class levels of the sub-watersheds before and after disturbances. Legendre and Fortin (1989) described Moran's I correlogram in more detail.

\section{Results}

At the landscape level, after the earthquake, the Number of Patches, the Total Edge, and the Interspersion and Juxtaposition Index of all patches across the watershed landscape increased by $8.2-10.9 \%$, but Mean Patch Size, Standard Deviation of Patch Size, and Mean Proximity Index declined by 5.9-9.7\% (Figure 2). Conversely, after Typhoon Xangsane, the Number of Patches, the Total Edge, and the Interspersion and Juxtaposition Index of all patches across the watershed decreased by 1.6-6.1\%, whereas Mean Patch Size, Standard Deviation of Patch Size, and Mean Proximity increased by $3.5-6.4 \%$ at the landscape level, as shown in Figure 2. Figure 2 also shows that after Typhoon Toraji, Number of Patches, Mean Patch Size, Total Edge, Mean Shape Index, and Interspersion and Juxtaposition Index of all patches across the watershed were almost unaffected (Change $<1.6 \%$ ), whereas the Mean Proximity Index increased considerably, by $23.57 \%$, at the landscape level. The mean patch fractal dimension of all patches across the entire watershed at the landscape level after the disturbances was almost the same as that before.

At the forest class level, after the earthquake, Number of Patches, Total Edge, and the Interspersion and Juxtaposition Index of forest patches across the entire watershed landscape increased by 2.5-5.3\%. However, Mean Patch Size, Standard Deviation of Patch Size, Mean Shape Index, and Mean Proximity Index decreased by 2.1-6.2\% (Figure 3). Conversely, after Typhoon Xangsane, the Number of Patches of the forest across the entire watershed was 2.6\% lower, but the Mean Patch Size and the Standard Deviation of the Patch Size was 1.8-3.0\% higher; the Interspersion and Juxtaposition Index was $4.0 \%$ higher. After Typhoon Toraji, Number of Patches, Total Edge, and Mean Proximity of forest patches across the watershed were $14.6 \%, 4.2 \%$, and 9.2\% higher, but Mean Patch Size and Standard Deviation of Patch Size were 12.2\% and $5.9 \%$ lower, respectively, at the forest class level.

After the earthquake, the Number of Patches of grassland across the watershed landscape was $31.2 \%$ higher, Total Edge was $14.0 \%$ higher, and Interspersion and Juxtaposition Index was $18.4 \%$ higher. However, Mean Patch Size was $19.6 \%$ lower, Standard Deviation of Patch Size was $14.0 \%$ lower, and Mean Proximity Index was $8.6 \%$ lower (Figure 4). Conversely, after Typhoon Xangsane, the Number of Patches of grassland in the watershed was $22.6 \%$ lower, Total Edge was $12.8 \%$ lower, and the Interspersion and Juxtaposition Index was 9.1\% lower; however, the Mean Patch Size was $20.0 \%$ higher, Standard Deviation of Patch Size was $11.4 \%$ higher, and Mean Proximity was $3.2 \%$ higher. After Typhoon Toraji, the Number of Patches of grassland across the watershed was $7.9 \%$ higher and Total Edge was 3.7\% higher, but Mean Patch Size was $5.6 \%$ lower and Mean Proximity Index was $4.1 \%$ lower.

At the farmland class level, after the earthquake, the Number of Patches, Total Edge, and the Interspersion and Juxtaposition Index of farmland patches across the watershed were 5.8-10.9\% higher; however, Mean Patch Size, Standard Deviation of Patch Size, and Mean Proximity were 11.9-19.0\% lower (Figure 4). After Typhoon Xangsane, the Number of Patches, the Standard Deviation of Patch Size, the Total Edge, Mean Proximity, and the Interspersion and Juxtaposition Index of farmland patches across the watershed were $5.1 \%, 21.3 \%, 5.1 \%, 40.1 \%$, and $4.9 \%$, respectively, lower; only the Mean Shape Index was unaffected. After Typhoon Toraji, only the Number of Patches of farmland across the watershed increased, and did so by $8.9 \%$, unlike Mean Patch Size, Standard Deviation of Patch Size, Mean Proximity, and the Interspersion and Juxtaposition Index, which declined by $17.3 \%, 33.5 \%$, $45.7 \%$, and $7.3 \%$, respectively.

After the earthquake, Mean Patch Size, Standard Deviation of Patch Size, Mean Shape, Mean Proximity, and the Interspersion and Juxtaposition Index were $69.4 \%, 11.2 \%, 8.7 \%, 21.5 \%$, and $28.3 \%$ lower, respectively; however, the Number of Patches of bare land across the watershed landscape decreased by $37.3 \%$. In contrast, after Typhoon Xangsane, Number of Patches, Standard Deviation of Patch Size, Total Edge, and 

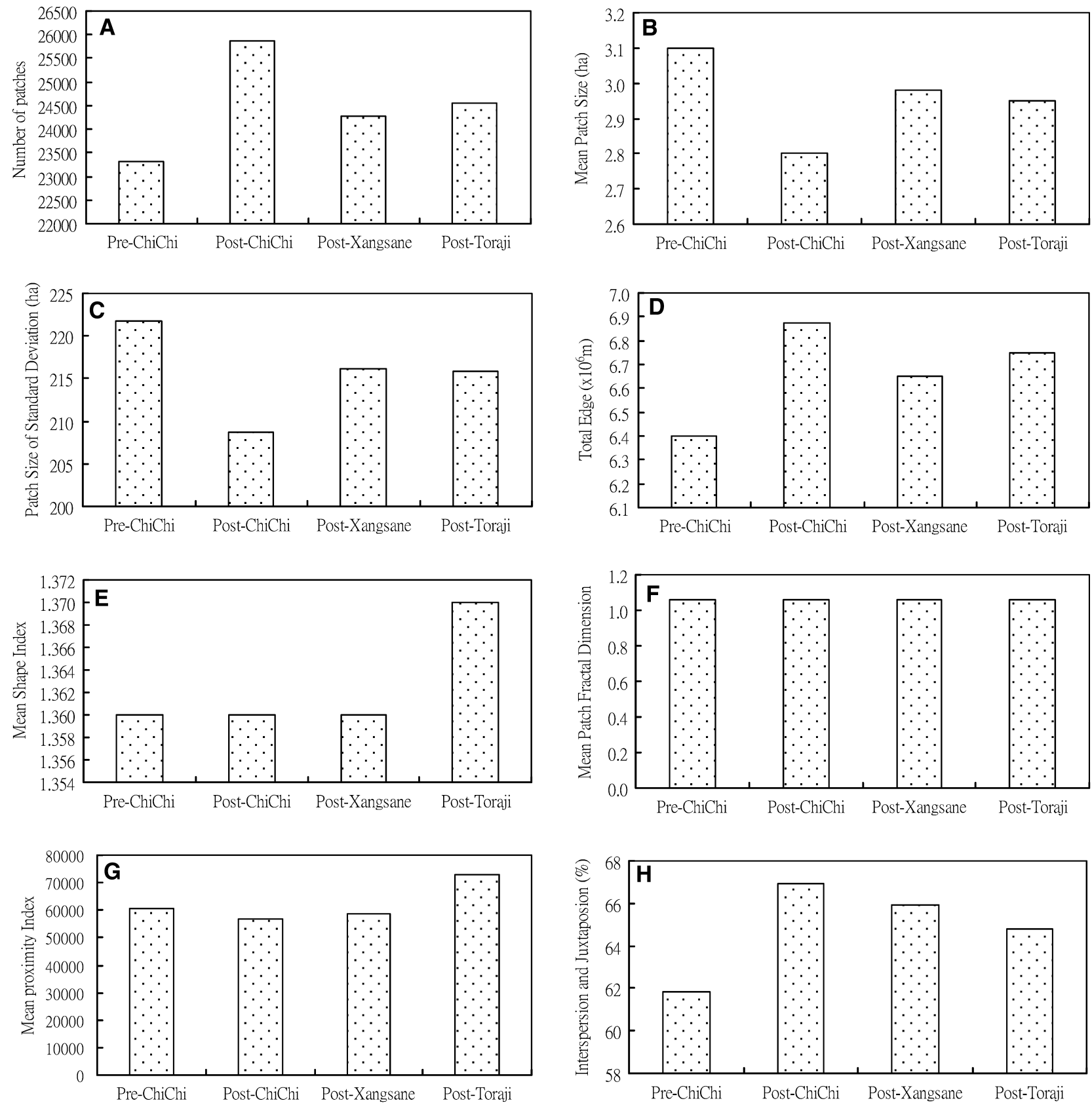

\section{$\square$ Landscape}

Figure 2. Landscape metrics of landscape patch (A) NP; (B) MPS; (C) PSSD; (D) TE; (E) MSI; (F) MPFD; (G) MPI; (H) IJI.

Mean Proximity of the bare land patches across the watershed were $88.0 \%, 10.1 \%, 42.78 \%$, and $18.7 \%$ higher, respectively (Figure 5). However, the Mean Patch Size, Mean Shape, and the Interspersion and Juxtaposition Index were 21.3\%, 5.8\%, and $11.8 \%$ lower, respectively. After Typhoon Toraji, Number of
Patches and Total Edge of bare land across the watershed were $38.6 \%$ and $4.3 \%$ lower, respectively. However, Mean Patch Size, Standard Deviation of Patch Size, Mean Shape, Mean Proximity Index, and the Interspersion and Juxtaposition Index were $79.2 \%$, $70.2 \%, 5.4 \%, 128.5 \%$, and $2.8 \%$ higher, respectively. 

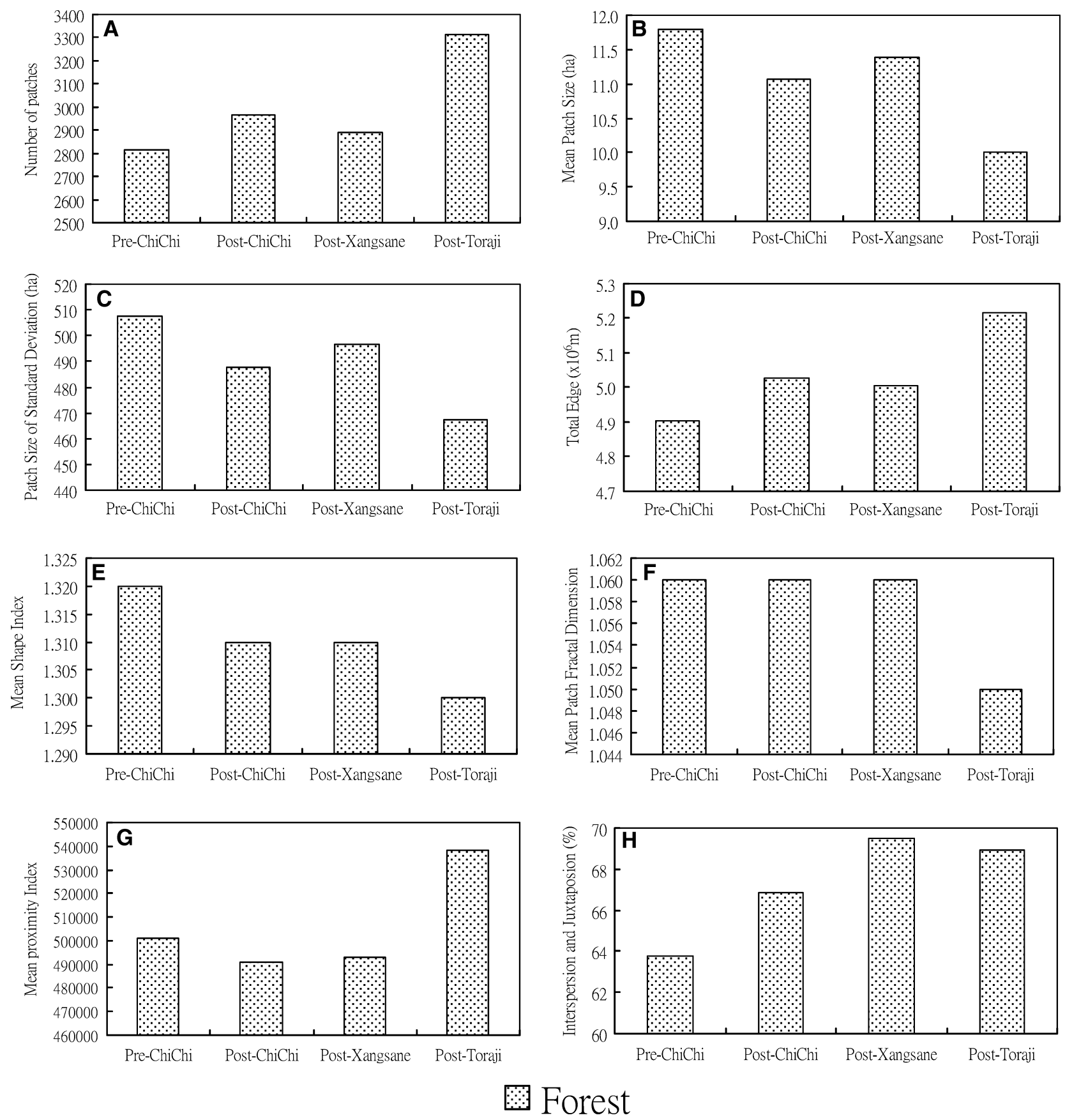

Figure 3. Landscape metrics of forest patch (A) NP; (B) MPS; (C) PSSD; (D) TE; (E) MSI; (F) MPFD; (G) MPI; (H) IJI.

\section{Multivariate Statistical Analysis of Sub-Watershed Landscape}

One-way dependent samples ANOVA results showed that differences between seven of the eight tested landscape metrics of watershed landscape and the bare land in sub-watersheds were significant (Table 2). Differences in six of eight landscape metrics for the forest and farmland, caused by the disturbances, were significant. For the grassland patches tested, the differences were significant for five of the eight metrics. The disturbances did not significantly change the Mean Patch Fractal Dimensions or the Mean Shape Indices of the forest and the farmland. The disturbances do not significantly affect the Standard Deviation of the Patch Size and the Mean Patch Index of the sub-watershed 

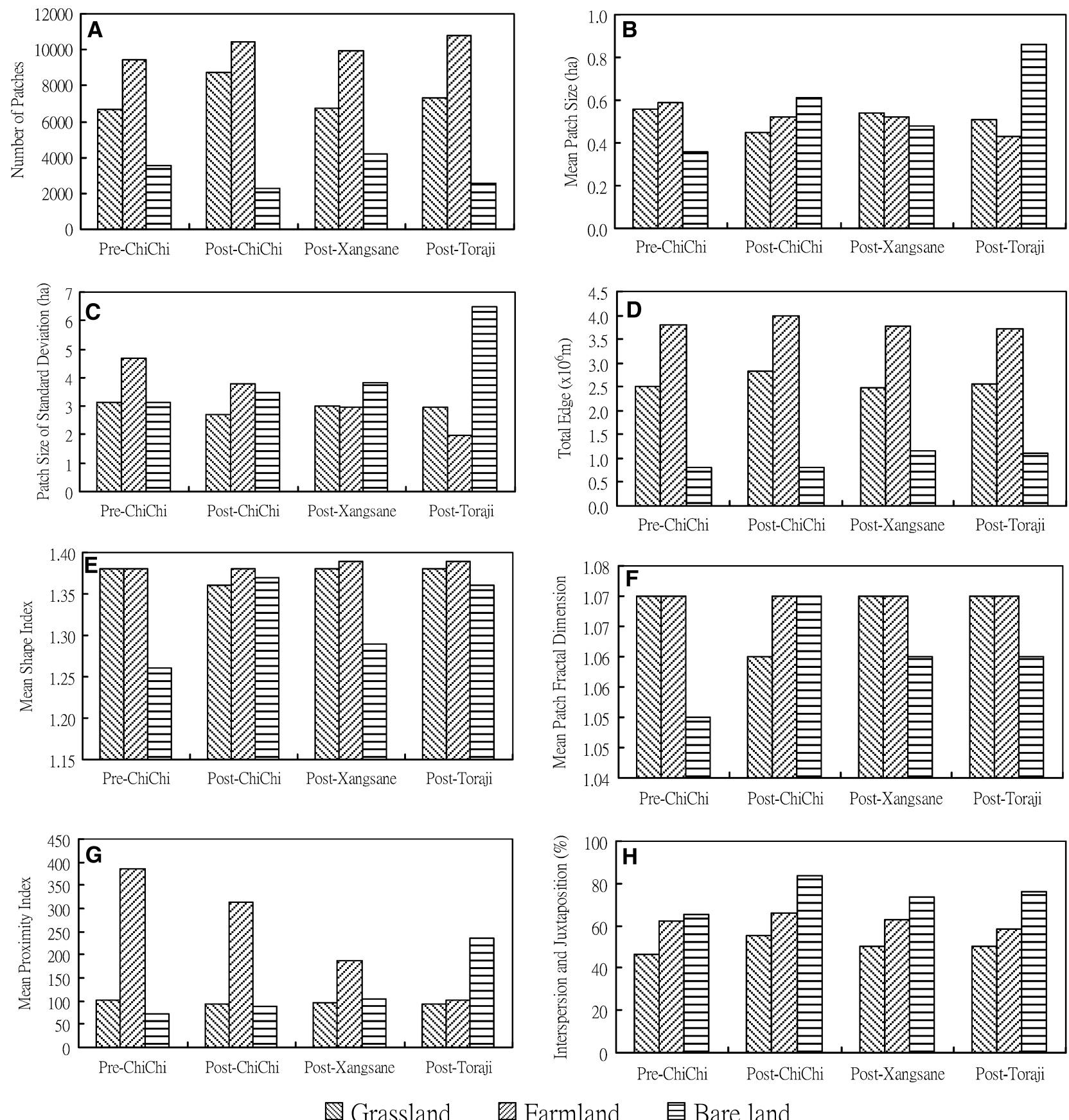

Figure 4. Landscape metrics of farmland, bare land, and grassland patch (A) NP; (B) MPS; (C) PSSD; (D) TE; (E) MSI; (F) MPFD; (G) MPI; (H) IJI.

grassland. Therefore, paired $t$ tests of the Standard Deviation of Patch Size, the Mean Shape, and Mean Proximity Index of sub-watershed grassland patches were performed to verify the ANOVA results (Table 3). The Chi-Chi earthquake significantly changed the Standard Deviation of the Patch Size of sub-watershed grassland, but the Xangsane and Toraji typhoons did not. The Chi-Chi earthquake and Typhoon Xangesane, but not Typhoon Toraji, significantly changed the Mean Shape Indices of sub-watershed grassland patches.

The seven landscape metrics (Mean Patch Size, Total Edge, Patch Size of Standard Deviation, Mean Shape Index, Mean Patch Fractal Dimension, Mean Proximity Index, and Interspersion and Juxtaposition Index) of 

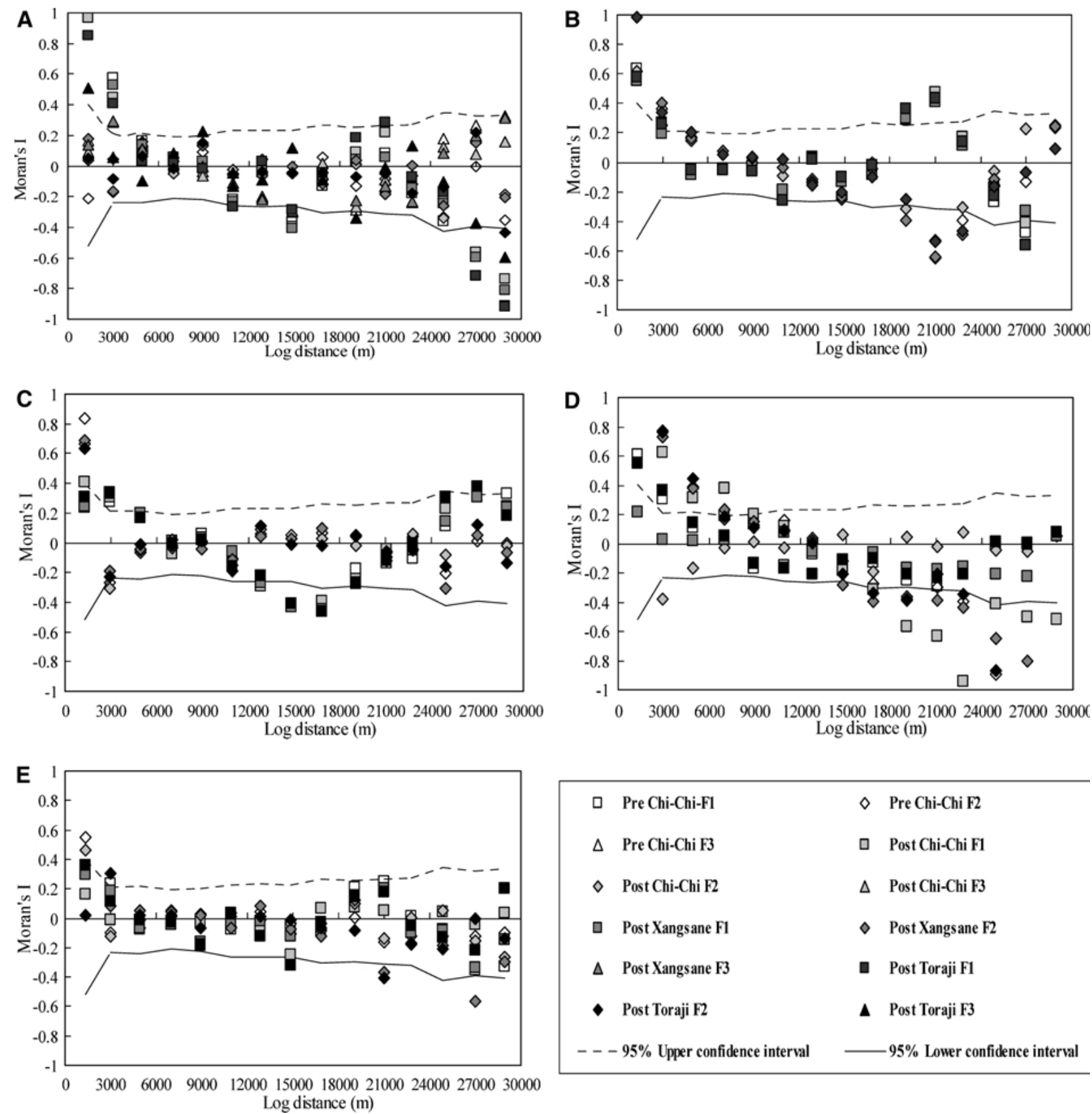

Figure 5. Moran's I of sub-watershed factor score in (A) Landscape; (B) Forest; (C) Farmland; (D) Grassland; (E) Bare land.

41 sub-watersheds were calculated to demonstrate the landscape variation before and after the disturbances at the landscape and class levels. The three-factor model explains $83.18 \%$ of total variation of landscape metrics data for the 41 sub-watershed landscapes before and after the disturbances, as listed in Table 4. At the class level, multi-temporal factor analysis results grouped seven metrics to be two-factor models for forest, grassland, farmland, and bare land across the sub-watershed
(Table 4), with $73.26 \%, 78.15 \%, 70.00 \%$, and $73.49 \%$ of total variations, respectively.

The first factor displayed high factor loadings $(>0.8)$ on Total Edge and Mean Proximity Index, which represented the edge and isolation of patches at landscape level of the sub-watersheds before and after the disturbances. The first factor represented edge and isolation of all patches and explained $33.05 \%$ of the total landscape metrics data variation for the 41 sub-watershed 
Table 2. ANOVA significant levels of landscape metrics for sub-watersheds before and after disturbances

\begin{tabular}{llllll}
\hline & \multicolumn{3}{c}{ Class } \\
\cline { 2 - 6 } Metrics & Landscape & Forest & Farmland & Grassland & Bare land \\
\hline NP & $0.000^{* * *}$ & $0.012^{*}$ & $0.000^{* * *}$ & $0.000^{* * *}$ & $0.000^{* * * *}$ \\
MPS & $0.000^{* * *}$ & $0.001^{* *}$ & $0.000^{* * *}$ & $0.018^{*}$ & $0.000^{* * *}$ \\
PSSD & $0.000^{* * *}$ & $0.000^{* * *}$ & $0.000^{* * *}$ & 0.251 & $0.000^{* * * *}$ \\
TE & $0.000^{* * *}$ & $0.000^{* * *}$ & $0.010^{*}$ & $0.000^{* * *}$ & $0.000^{* * *}$ \\
MPFD & 0.411 & 0.146 & 0.079 & 0.155 & 0.072 \\
MSI & $0.002^{* *}$ & 0.131 & 0.069 & $0.013^{*}$ & $0.031^{*}$ \\
MPI & $0.000^{* *}$ & $0.000^{* * *}$ & $0.000^{* * *}$ & 0.518 & $0.000^{* * *}$ \\
IJI & $0.000^{* * *}$ & $0.000^{* * *}$ & $0.006^{* *}$ & $0.000^{* * *}$ & $0.000^{* *}$ \\
\hline
\end{tabular}

*Significant at $P<0.05$.

**Significant at $P<0.01$.

*** Significant at $P<0.001$.

Table 3. Paired $t$ significant levels of landscape metrics of sub-watershed grassland before and after disturbances

\begin{tabular}{llll}
\hline & & \multicolumn{2}{c}{ Metrics } \\
\cline { 2 - 4 } Time periods & \multicolumn{1}{c}{ PSSD } & MSI & MPI \\
\hline Pre Chi-Chi-Post Chi-Chi & $0.000^{* * *}$ & $0.009^{* *}$ & 0.190 \\
Post Chi-Chi-Post Xangsane & 0.150 & $0.012^{*}$ & 0.329 \\
Post Xangsane-Post Toraji & 0.432 & 0.853 & 0.426 \\
\hline
\end{tabular}

* Significant at $P<0.05$.

**Significant at $P<0.01$.

*** Significant at $P<0.001$.

Table 4. Multi-temporal factor loadings for the landscape metrics

\begin{tabular}{|c|c|c|c|c|c|c|c|c|c|c|c|}
\hline \multirow[b]{3}{*}{ Factor } & \multicolumn{11}{|c|}{ Level } \\
\hline & \multicolumn{3}{|c|}{ Landscape } & \multicolumn{2}{|c|}{ Forest } & \multicolumn{2}{|c|}{ Grassland } & \multicolumn{2}{|c|}{ Farmland } & \multicolumn{2}{|c|}{ Bare land } \\
\hline & 1 & 2 & 3 & 1 & 2 & 1 & 2 & 1 & 2 & 1 & 2 \\
\hline ISSD & 0.68 & -0.05 & 0.69 & 0.95 & 0.16 & 0.91 & 0.32 & 0.98 & 0.07 & 0.98 & 0.04 \\
\hline MPI & 0.88 & -0.05 & 0.33 & 0.95 & -0.07 & 0.91 & 0.26 & 0.94 & -0.00 & 0.89 & -0.02 \\
\hline TE & 0.93 & -0.16 & -0.09 & 0.66 & -0.33 & 0.21 & 0.69 & 0.54 & -0.15 & 0.81 & -0.14 \\
\hline IJI & 0.33 & 0.50 & -0.02 & 0.38 & -0.21 & 0.31 & 0.53 & -0.04 & 0.28 & 0.25 & -0.18 \\
\hline MSI & -0.31 & 0.87 & -0.17 & -0.36 & 0.89 & 0.46 & 0.85 & 0.18 & 0.97 & 0.04 & 0.98 \\
\hline MPS & 0.02 & -0.13 & 0.98 & 0.34 & 0.87 & 0.90 & 0.42 & 0.79 & 0.45 & 0.76 & 0.43 \\
\hline MPFD & -0.09 & 0.93 & -0.09 & -0.51 & 0.71 & 0.21 & 0.89 & 0.00 & 0.94 & -0.05 & 0.96 \\
\hline Variance $(\%)$ & 33.05 & 27.46 & 22.67 & 41.18 & 32.08 & 40.98 & 37.17 & 39.89 & 30.20 & 43.49 & 30.45 \\
\hline Cum. variance (\%) & & 83.18 & & & 73.26 & & 78.15 & & 70.00 & & 73.49 \\
\hline
\end{tabular}

Bold font: high positive factor loading $(>0.8)$.

landscapes before and after the disturbances (Table 4). The second factor exhibited a high positive factor loading $(>0.8)$ on Mean Shape Index and Mean Patch Fractal Dimension, and represented the shape complexity of all patch types at the watershed landscape. Moreover, the second factor is associated with perimeter-area fractal, which measures complexity and perimeter-area scaling of patches and explains $27.46 \%$ of landscape metrics data for the 41 sub-watershed landscapes before and after the disturbances (Table 4). The third factor exhibited highly positive factor loading $(>0.8)$ on Mean Patch Size and represented patch size of the watershed landscape and explained $22.67 \%$ of the landscape metrics data for the 41 sub-watershed landscapes before and after the disturbances (Table 4). Moreover, Patch Size of Standard Deviation exhibited moderate factor loadings $(>0.6)$ both on the first and the third factors. 
In multi-temporal factor analysis of the seven landscape metrics of forest patches across 41 sub-watersheds, the first factor exhibited high factor loadings on Patch Size of Standard Deviation and Mean Proximity Index and represented variation and isolation of forest patches across the sub-watersheds before and after the disturbances. The first factor explains $41.18 \%$ of the total variation of landscape metrics data for the forest patches of 41 sub-watershed landscapes before and after the disturbances, as listed in Table 4. The second factor had positive factor loading on Mean Shape Index and Mean Patch Size and represented shape complexity and size of forest patches across the subwatersheds. Moreover, the second factor was moderately (factor loading $>0.7$ ) associated with Mean Patch Fractal Dimension and explained $32.08 \%$ of landscape metrics data for the 41 sub-watershed landscapes before and after the disturbances (Table 4).

The multi-temporal factor analysis results of the seven landscape metrics of grassland patches across 41 sub-watersheds illustrated that the first factor of the two-factor model exhibited high factor loadings on Patch Size of Standard Deviation, Mean Patch Size, and Mean Proximity Index and represented variation, size, and isolation of grassland patches across the subwatersheds before and after the disturbances, as listed in Table 4 . The first factor presented the variation and isolation of grassland patches and explained $40.98 \%$ of the total variation of landscape metrics data for the grassland patches of 41 sub-watersheds before and after the disturbances (Table 4). The second factor had positive factor loadings on Mean Shape Index and Mean Patch Fractal Dimension, and represented shape complexity of grassland patches across the sub-watersheds. Moreover, the second factor was moderately associated with Total Edge and explains $37.17 \%$ of the grassland's landscape metrics data of 41 sub-watershed landscapes before and after the disturbances (Table 4).

In the multi-temporal factor analysis of farmland patches across 41 sub-watersheds, the first factor of the two-factor model exhibited factor loadings highly on Patch Size of Standard Deviation and Mean Proximity Index and moderately on Mean Patch Size, and represented variation, isolation, and size of farmland patches across the sub-watersheds before and after the disturbances, as listed in Table 4 . The first factor presented the variation and isolation of farmland patches and explained $39.89 \%$ of the total variation of landscape metrics data for farmland of the 41 sub-watersheds before and after the disturbances (Table 4). The second factor exhibited highly positive factor loadings on Mean Shape Index and Mean Patch Fractal
Dimension, represented shape complexity of farmland patches across the sub-watersheds, and explained $37.17 \%$ of landscape metrics data of farmland for the farmland of 41 sub-watershed landscapes before and after the disturbances (Table 4).

The multi-temporal factor analysis results of the seven landscape metrics of bare land patches across 41 sub-watersheds revealed that the first factor of the twofactor model exhibited factor loadings highly on Patch Size of Standard Deviation, Mean Proximity Index and Total Edge and moderately on Mean Patch Size, and represented variation, isolation, edge, and size of bare land patches across the sub-watersheds before and after the earthquake and typhoons (Table 4). The first factor presented edge and isolation of bare land patches and explained $43.49 \%$ of the total variation of landscape metrics data for the bare land of 41 sub-watersheds before and after the disturbances (Table 4). The second factor had highly positive factor loadings on Mean Shape Index and Mean Patch Fractal Dimension, presented shape complexity of bare land patches across the sub-watersheds, and explained $30.45 \%$ of landscape metrics data of bare land for the bare land of 41 sub-watershed landscapes before and after the disturbances (Table 4).

\section{Variation of Landscape of Sub-Watersheds}

Figure 5A illustrates that first factor scores, representing the edge and isolation of patches for sub-watershed landscapes before and after disturbances, had positive spatial correlations among sub-watersheds at a distance approximate less than $8000 \mathrm{~m}$ except the first factor scores after Typhoon Toraji, but not at distances of between $8000 \mathrm{~m}$ and 24,000 m. The spatial correlations of the first factor scores among sub-watersheds are close to zero at distances greater than $8000 \mathrm{~m} \mathrm{ex}$ cept those at distances greater than $24,000 \mathrm{~m}$. The second factor scores of sub-watersheds, representing the shape complexity of the patches of sub-watershed landscape, had spatial correlations among sub-watersheds periodically close to zero at all distances. Figure 5B shows that first factor scores, representing variation and isolation of forest patches of sub-watersheds, had positive spatial correlations among subwatersheds at distances approximately less than 5000 $\mathrm{m}$. The second factor scores, representing shape complexity of forest patches for sub-watershed forest patches, had a positive correlation among sub-watersheds at distances approximately less than $11,000 \mathrm{~m}$. The correlations of the first factor scores among subwatersheds are close to zero at distances greater than $5000 \mathrm{~m}$ except those at distances from $18,000 \mathrm{~m}$ to $24,000 \mathrm{~m}$. The correlations of second factor scores 
among sub-watersheds are close to zero at distances greater than $1100 \mathrm{~m}$ except distances from 18,000 $\mathrm{m}$ to $24,000 \mathrm{~m}$. Moreover, the spatial correlations of factors before and after disturbances had similar tendencies and were slightly different. Figure $5 \mathrm{C}$ shows that factor scores had positive spatial correlations among subwatersheds at distances approximately less than $1500 \mathrm{~m}$ for the first factors representing variation and isolation of sub-watershed farmland patches, and $9000 \mathrm{~m}$ for the second factors representing shape complexity of subwatersheds farmland patches. Moreover, the correlations of second factor scores had periodical tendencies. The spatial correlations of all factors before and after disturbances had similar tendencies. Figure 5D displays that first factor scores, representing variation and isolation of sub-watershed grassland patches, had various positive spatial correlations among sub-watersheds in disturbed periods at distances that ranged approximately from $3000 \mathrm{~m}$ to $12,000 \mathrm{~m}$, respectively. The spatial correlations of the first factors before and after disturbances likely reach zero at distances approximately greater than $10,000 \mathrm{~m}$ to $12,000 \mathrm{~m}$ except the first factor after the Chi-Chi earthquake, the second factor after Typhoon Xangsane, and the second factor after Typhoon Toraji for sub-watershed grassland patches. The spatial correlation tendencies of factors before and after disturbances are significantly different. Figure 5E displays no significant Moran's I tendencies for factors representing variation, isolation, and shape complexity for sub-watershed bare land patches before and after disturbances. Spatial correlations for all factors among sub-watershed bare land patches at distances less than $3000 \mathrm{~m}$ are considerably positive except the first factor after the Chi-Chi earthquake and the second factor after Typhoon Toraji. The Moran's I tendencies of all factors for sub-watershed bare land patches before and after disturbances are considerably different.

\section{Discussion}

\section{Watershed Landscape Patterns}

The landscape metric results showed that all patches were moderately fragmented, interspersed with patches of other types, and isolated from patches of the same type across the entire Chenhyuland watershed at the landscape level after the Chi-Chi earthquake. The earthquake dominated the change in the patch characteristics of the entire watershed landscape. However, after Typhoon Xangsane, all patches tended to become larger, interspersed with other patch types, and less isolated from the same type of patches in the entire Chenyulan watershed compared to the landscape after the earthquake. After Typhoon Toraji, all patches in the watershed landscape were more fragmented, more irregular, and less interspersed, but considerably more isolated than after Typhoon Xangsane. However, at the landscape level, the earthquake impacted the fragmentation, isolation, and interspersion of the entire Chenyulan watershed landscape, but Typhoon Xangsane had slightly dissimilar impacts. These phenomena have been caused by the different disturbances and energy types. Some landscape restoration projects had begun before Typhoon Xangsane hit Taiwan and had influenced the watershed. Typhoon Toraji slightly influenced fragmentation and patch shape, but considerably affected the isolation of the landscape patches. Accordingly, the central typhoon's heavier rainfall that fell directly across the study area caused the erosion of the soil, which had already been loosened by the Chi-Chi earthquake and Typhoon Xangsane. Large disturbances do not create large homogeneous patches of damage (Foster and others 1998). These results verify that disturbances create very complex heterogeneous patterns across the landscape, because they may affect some areas but not others, and the severity of the disturbances frequently varies considerably within the affected area (Turner and others 2001). The landscape metrics also indicate that the disturbances and disturbance regime are characterized by a variety of attributes, including size, frequency, intensity, severity, and shape (Turner and others 2001; Boose and others 2001). The disturbances may have a cumulative impact on the isolation of the watershed landscape in the study area at the landscape level.

Disturbances are not the only destructive and restorative causes of modification of the geomorphic landscape or the structure and composition of the forest that occur between disturbances (Scatena and Lugo 1995). At the class level, the landscape metrics of forest patches showed that forest patches were slightly fragmented, but tended to be regularly shaped, and interspersed with patches of other types and isolated from those of the same type in the Chenhyuland watershed after the Chi-Chi earthquake. After Typhoon Xangsane, forest patches exhibited slightly changed fragmentation, shape, and isolation, but were interspersed with patches that differed from those with which they were interspersed after the Chi-Chi earthquake. After Typhoon Toraji, forest patches were slightly less interspersed with other patches, less isolated from patches of the same type, exhibited a narrower range of patch sizes, and were less convoluted, but more fragmented. However, the earthquake and the typhoons impacted the fragmentation, shape, isolation, and interspersion of forest patches of the 
Chenyulan watershed landscape, whereas Typhoon Xangsane had only strongly affected the forest interspersion. These phenomena indicate that small gaps in tropical mountain rainforests are not associated with landslides, but that catastrophic windthrow from hurricanes causes landslides (Remme and others 1998). Moreover, regional scale patterns of forest damage are controlled by wind gradients that are governed by the sizes of the hurricane, the intensity of the storm, and its track (Foster and others 1998).

Some field investigation results in 2003 of this study confirm that the soil legacies created by the uprooting of trees and landslides triggered by windthrow and intense precipitation are inherent aspects of the soil dynamics and the landscape patterns (Stephens 1956; Foster and others 1998). Grassland patches of the Chenyulan watershed were considerably fragmented, interspersed, and isolated, but the shapes of the grasslands tended to be regular and simple after the Chi-Chi earthquake. However, after Typhoon Xangsane, grassland patches were less fragmented, less interspersed, and less isolated, but grassland shapes tended to be considerably larger and slightly more irregular with complex perimeters across the Chenhyuland watershed than after the earthquake. After Typhoon Toraji, grassland patches were fragmented and isolated, but became smaller than those after Typhoon Xangsane. Moreover, the shapes and interspersion of grassland patches were almost the same in all cases, perhaps because the restorations of the landscape were focused primarily on the grassland and bare land after the earthquake. However, Typhoon Toraji destroyed some of the restorative works.

Farmland patches were considerably more fragmented, interspersed, and isolated in the Chenhyuland watershed after the Chi-Chi earthquake. After Typhoon Xangsane, all farmland patches were considerably isolated, but slightly less fragmented with less interspersion among patches of other types across the Chenyulan watershed than after the earthquake. After Typhoon Toraji, all farmland patches were more fragmented and strongly isolated, but fewer were interspersed with patches of other types. However, the continuous disturbances had a considerable cumulative impact on the variation and isolation of manmade patches.

Bare land patches were considerably more interspersed with patches of types, tended be regularly and simply shaped, and were strongly isolated in the Chenhyuland watershed after the Chi-Chi earthquake. Landslides may also be more likely to recur in the same area in the Luguillo Experimental Forest of Puerto Rico (Myster and others 1997). These landslide phe- nomena were also found in some field investigations in this study after Typhoon Toraji in the study watershed. The investigation results of this study also confirm that rainfall associated with Typhoon Toraji increased the landslide area mostly by enlarging and/or combining after the Chi-Chi earthquake (Cheng and others 2005; Lin and others 2003). After Typhoon Xangsane, the total area of bare land patches in the Chenyulan watershed increased; they were markedly fragmented, but less isolated, less interspersed, more regularly and simply shaped than the bare land patches after the earthquake. After Typhoon Toraji, bare land patches were significantly larger, irregularly shaped, and highly isolated from patches of the same type, as well as slightly interspersed with patches of other types in the Chenyulan watershed. The results referred to above showed that the proportion of surface area affected by landslides during Typhoon Toraji increased with proximity to the Chelungpu fault. Even in areas that underwent no landsliding during the earthquake, the substrate was preconditioned to fail because of loss of cohesion and frictional strength of the hill-slope rock mass caused by strong seismic ground motion (Dadson and others 2004). The earthquake and typhoons had different impacts on the bare land patches in the watershed of interest. The continuous disturbances considerably affected the bare land patches. These results also confirm our ground truth investigation results that flood and landslides caused by the intense and extended precipitation that accompanies hurricanes also markedly affect ecological processes and trophic structures (Scatena and Larsen 1991; Foster and others 1998).

Similar to related studies (Cushman and other 2000; Johnson and others 2001; Apan and others 2002; Staus and others 2002; Liu and others 2003; Baldwin and others 2004; Croissant 2004; Pan and others 2004; Zhang and others 2004), remote sensing images were classified by classification techniques with 1/5000 aerial photographs, ground truth data, and spatial information in this study watershed. Prior to the classifications of images, 109 sampling points of 756 ground truth points were determined by filed investigations with GPS in the study watershed in 2003. The phenomena of landscape pattern changes were also partially confirmed by the field investigations of the watershed in this study. However, the more field investigations, the more accuracy for classifying remote sensing images and presenting landscape patterns. Furthermore, the lack of detailed field information of the entire watershed may limit the presentation and interpretations of landscape pattern changes caused by disturbances in this study. 


\section{Spatial Variations of Watershed Landscape}

The multi-temporal factor analysis results revealed that the sub-watersheds with a high factor score of factor 1 at the landscape level had landscape with high Total Edge, Mean Proximity, and Patch Size Deviation in all patch types. Sub-watersheds with a high factor score of factor 2 had landscapes with high values on Mean Shape Index and Mean Patch Fractal Dimension. Moreover, sub-watershed landscapes with high factor score of factor 3 had high values on Mean Patch Size and Patch Size Deviation. The three-factor model results indicated that the major influence of disturbances was the landscape variation of sub-watersheds on isolation, shape complexity, and size of patches, respectively. At class level, two-factor models illustrated that the major impact of disturbances were on the subwatersheds' landscape variation on isolation and shape complexity of forest, grassland, farm, and bare land patches.

Spatial correlation results indicate all disturbances gradually and markedly affected the spatial variations in the patterns of grassland and the bare land patches of the sub-watersheds, and slightly affected the spatial variations in the patterns of the landscape and the forest patches of the sub-watersheds. Before the ChiChi earthquake, the spatial distribution of sub-watershed grassland patches were positively correlated among sub-watersheds at a distance of less than 8000 $\mathrm{m}$, but are more likely to be randomly distributed at a distance that exceeds $8000 \mathrm{~m}$. The Moran's I values of the factors that represent the variation, the isolation, and the complexity of sub-watershed grassland patches clearly changed during the disturbances at various distances. After Typhoon Xangsane, the variation and isolation of sub-watershed grassland patches became more randomly distributed than after other disturbances. The Chi-Chi earthquake clearly changed the spatial variation of shape complexity of sub-watershed grassland patches. The spatial variations of the subwatershed bare land patches were almost randomly distributed over the entire watershed, showing only clustered patterns on a very small scale. These landscape spatial variation results imply that the earthquake with high magnitude was a starter to create landscape variation in space in the Chenyulan watershed. However, disturbances create very complex heterogeneous patterns across the landscape, because the disturbance may affect some areas but not others, and the severity of the disturbance often varies considerably within the affected area (Turner and others 2001) in landscape and class levels. Even though the Taiwan Government has reduced the human activity in the study area, the background transition of the watershed landscape is important for evaluating the impact of disturbance in the area of interest, to delineate the impacts of disturbances and the background transition of the landscape of the watershed.

\section{Conclusions}

These analyses of spatial patterns of the landscape, applied to the entire watershed and the sub-watersheds of the Chenyulan watershed in central Taiwan that were affected by the Chi-Chi earthquake, and the typhoons Xangsane and Toraji, yielded landscape metrics and identified the numerous factors that were associated with them. Landscape metrics, multivariate analysis, and autocorrelation analysis can be combined with remote sensing images to analyze fully the changes of landscape spatial patterns and variations of the study watershed caused by disturbances. Multi-temporal factor analysis and spatial autocorrelation grouped landscape metrics of sub-watersheds in landscape and class levels to show the impact of the earthquake and typhoons on the spatial variations and patterns of the landscape. Metrics are grouped according to their relevance to isolation, and the shape and size of patches. The spatial autocorrelation of each factor score of subwatersheds explained much of the spatial variance in landscape patterns and the changes in the sub-watersheds associated with the disturbances. The Chi-Chi earthquake created patches that were considerably fragmented, interspersed with patches of other types, and moderately isolated from patches of the same type across the entire Chenhyuland watershed at landscape level. The earthquake also influenced the isolation, size, and shape complexity of patches at the landscape level. After the earthquake, the typhoons with different paths and magnitudes variously affected the landscape patterns and the variations at landscape level, but Typhoon Toraji more strongly affected them than did Typhoon Xangsane. At the class level, the disturbances had a greater impact on the landscape and the patterns of grassland and bare land than on the forest and farmland in the watershed. Moreover, the cumulative spatial and temporal impacts of the disturbances at the landscape and class levels in the study area were not always evident. The cumulative impacts of the disturbances also depended on the magnitudes, the attack paths, and the land uses. This study is a first attempt to evaluate the impact of disturbances on landscape patterns and variations in Taiwan, using landscape metrics, multivariate statistics, and spatial autocorrelation methods. Further work, involving simulations, will extend our knowledge of the effect of disturbances on 
landscape patterns, to facilitate the management of the watershed. Moreover, further study should also focus on the effects of the uncertainties in the classifications of the remote sensing images for landscape pattern analysis. The detail and accurate field investigations and information of the entire study watershed should be done prior to and after the image classification and landscape pattern analysis. The background transition of the landscape is also important in assessing the real impacts of disturbances in the study area.

\section{Acknowledgments}

The authors would like to thank the Soil and Water Conservation Bureau of the Republic of China for financially supporting this research under Contract No. SWCB-92-026-08. The authors would also like to thank Mr. Dong-Po Deng for treatments of images and field investigations of the study area.

\section{Literature Cited}

Aguiar, M. R., and O. E. Sala. 1999. Patch structure, dynamics and implications for the functioning of arid ecosystems. Trends in Ecology and Evolution 14:273-277.

Apan, A.A., S. R. Raine, and M. S. Paterson. 2002. Mapping and analysis of changes in the riparian landscape structure of the Lockyer Valley catchment, Queensland, Australia. Landscape and Urban Planning 59:43-57.

Baldwin, D. J. B., K. Weaver, F. Schnekenburger, and A. H. Perera. 2004. Sensitivity of landscape pattern indices to input data characteristics on real landscapes: implications for their use in natural disturbance. Landscape Ecology 19:255-271.

Boose, E. R., D. R. Foster, and M. Fluet. 1994. Hurricane impacts to tropical and temperate forest landscape. Ecology Monographs 64:639-400.

Boose, R., K. E. Chamberlin, and D. R. Foster. 2001. Landscape and regional impact of hurricanes in New England. Ecology Monographs 71:27-48.

Cain, D., K. Riitters, and K. Orvis. 1997. A multi-scale analysis of landscape statistics. Landscape Ecology 12:199-212.

Central Weather Bureau (CWB). 1999. URL: http://scman. cwb.gov.tw/eqv3/eq_report/special/ 19990921/921 isomap.GIF.

Central Weather Bureau (CWB). 2000. URL:http://www. cwb.gov.tw/V4/typhoon/history/Data/ 2000XANGSANE. htm.

Central Weather Bureau (CWB). 2001. URL:http:// www.cwb.gov.tw/V4/typhoon/history/Data/2001TORAJI. htm.

Chang, J. C. 1997. Relationship between geomorphic environment and natural hazards in Chenyulan drainage basin. Bulletin of the Geographical Society of China 25:43-64.

Cheng, J. D., Y. C. Huang, H. L. Wu, J. L. Yeh, and C. H. Chang. 2005. Hydrometeorological and landuse attributes of debris flows and debris floods during Typhoon Toraji, July 29-30, 2001 in Central Taiwan. Journal of Hydrology 206:161-173.

Cifaldi, R. L., J. D. Allan, J. D. Duh, and D. C. Brown. 2004. Spatial patterns in land cover of exurbanizing watersheds in southeastern Michigan. Landscape and Urban Planning 20:107-123.

Collins, R. J., and G. W. Barrett. 1997. Effects of habitat fragmentation on meadow vole (Microtus pennsylvanicus) population dynamics in experimental landscape patches. Landscape Ecology 12:63-76.

Croissant, C. 2004. Landscape patterns and parcel boundaries: an analysis of composition and configuration of land use and land cover in south-central Indiana. Agriculture, Ecosystems and Environment 101:219-232.

Cumming, S., and P. Vrnier. 2002. Statistical models of landscape pattern metrics, with applications to regional scale dynamic forest simulations. Landscape Ecology 17:433444.

Cushman, S. A., and D. O. Wallin. 2000. Rate and patterns of landscape change in the Central Sikhote-alin Mountains, Russian Far East. Landscape Ecology 15:643-659.

Dadson, J. D., N. Hovius, W. B. Dade, J. C. Lin, M. L. Hsu, C. W. Lin, M. J. Horng, T. C. Chen, J. Milliaman, and C. P. Stark. 2004. Earthquake-triggered increase in sediment delivery from an active mountain belt. Geology 32:733-736.

DeMets, C., R. G. Gordon, D. F. Argus, and S. Stein. 1990. Current plate motions. Geophysical Journal International $104: 425-478$

Faccio, S. D. 2003. Effects of ice storm-created gaps on forest breeding bird communities in central Vermont. Forest Ecology and Management 186:133-145.

Fitzsimmons, M. 2003. Effects of deforestation and reforestation on landscape spatial structure in boreal Saskatchewan, Canada. Forest Ecology and Management 174:577-592.

Forman, R. T. T. 1995. Land Mosaics: The ecology of landscapes and regions. Cambridge University Press, Cambridge.

Foster, D. R., D. H. Knight, and J. F. Frankin. 1998. Landscape patterns and legacies resulting from large infrequent forest disturbances. Ecosystems 1:497-510.

Gamma Design Software. 1995. GS+: Geostatistics for the agronomic and biological sciences. Version 5.1. Gamma Design, Plainwell, MI.

Gardner, R.H., B. T. Milne, M. G. Turner, and R. V. O'Nell. 1987. Neutral models for the analysis of broad-scale landscape pattern. Landscape Ecology 1:19-28.

Griffith, J. A., E. A. Martinko, and K. P. Price. 2000. Landscape structure analysis of Kansas at three scales. Landscape and Urban Planning 52:45-61.

Gustafson, E. J. 1998. Quantifying landscape spatial pattern: what is the state of the art? Ecosystems 1:143-156.

Hansen, M. J., S. E. Franklin, C. G. Woudsma, and M. Peterson. 2001. Caribou habitat mapping and fragmentation analysis using Landsat MSS, TM, and GIS data in the North Columbia, Canada. Remote Sensing of Environment 77:50-65.

Hessburg, P. F., B. G. Smith, R. B. Salter, R. D. Ottmar, and E. Alvarado. 2000. Recent changes (1930s-1990s) in spatial 
patterns of interior northwest forests, USA. Forest Ecology and Management 136:53-83.

Hokit, D. G., B. M. Smith, and L. C. Branch. 1999. Effect of landscape structure in florida scrub-A population perspective. Ecological Application 9:124-134.

Honnay, O., K. Piessens, W. Van Landuyt, M. Hermy, and H. Gulinck. 2003. Satellite based land use and landscape complexity indices as predictors for regional plant species diversity. Landscape and Urban Planning 63:241-250.

Hudak, A. T., D. H. K. Fairbanks, and B. H. Brockett. 2004. Trends in fire patterns in a southern African savanna under alternative land use practices. Agriculture, Ecosystem, Environment 101:307-325.

Jibson, R. 1996. Use of landslides for paleoseismic analysis. Engineering Geology 43:291-323.

Johnson, G. D., W. L. Myers, G. P. Patil, and C. Taillie. 2001. Characterizing watershed-delineated landscapes in Pennsylvania using conditional entropy profiles. Landscape Ecology 16:597-610.

Lausch, A., and Herzog. 2002. Applicability of landscape metrics for the monitoring of landscape change: issues of scale, resolution and interpretability. Ecological Indicators 2:3-15.

Legendre, P. 1993. Spatial autocorrelation: trouble or new paradigm? Ecology 74:1659-1673.

Legendre, P., and M. J. Fortin. 1989. Spatial pattern and ecological analysis. Vegetatio 80:107-138.

Li, H. B., and J. F. Reynolds. 1994. A simulation experiment to quantify spatial heterogeneity in categorical maps. Ecology 75:36-55.

Li, H. B., and J. G. Wu. 2004. Use and misuse of landscape indices. Landscape Ecology 19:389-399.

Lin, C. W., C. L. Shieh, B. D. Yuan, Y. C. Shieh, S. H. Liu, and S. Y. Lee. 2003. Impact of Chi-Chi earthquake on the occurrence of landslides and debris flows: example from the Chenyulan River watershed, Nantou, Taiwan. Engineer Geology 71:49-61.

Lin, Y. P., T. P. Teng, and T. K. Chang. 2002. Multivariate analysis of soil heavy metal pollution and landscape patterns analysis in Changhua County in Taiwan. Landscape and Urban Planning 62:19-35.

Liu, Y., S. Nishyiyama, and T. Kusaka. 2003. Examining landscape dynamics at a watershed scale using Landsat TM imagery for detection of wintering Hooded Crane Decline in Yashiro, Japan. Environmental Management 31:365-376.

Lugo, A. E., and R. B. Waide. 1993. Catastrophic and background disturbance of tropical ecosystems at the Luquillo Experimental Forest. Journal of Bioscience 18:475-481.

Marshall, S., and M. Elliott. 1997. A comparison of univariate and multivariate numerical and geographical techniques for determining inter- and instraspecific feeding relationships in estuarine fish. Journal of Fish Biology 51:526-545.

McGarigal, K., and B. J. Marks. 1995. FRAGSTATS: Spatial Pattern Analysis Program for Quantifying Landscape Structure. USDA Forest Service, Pacific Northwest Research Station, Portland, OR, General Technical Report PNWGTR-351.

Moreira, F., P. G. Ferreira, F. C. Rego, and S. Bunting. 2001. Landscape change and breeding bird assemblages in northwestern Portugal: The role of fire. Landscape Ecology 16:175-187.

Myster, R. W., J. R. Thomlinson, and M. C. Larsen. 1997. Predicting landslide vegetation in patches on landscape gradients in Puerto Rico. Landscape Ecology 12:299-307.

Norusis, M. J. 1993. SPSS for Windows based system user's guide release 6.0, SPSS Inc., Chicago, IL.

O'Neill, R.V., J. R. Krummel, R. H. Gardner, G. Sugihari, B. Jackson, D. L. DeAngelis, B. T. Milne, M. G. Turner, G. Zygmunt, S. W. Christensen, V. H. Dale, and R. L. Graham. 1988. Indices of landscape pattern. Landscape Ecology 3:153-162.

Obeysekera, J., and K. Rutchey. 1997. Selection of scale for Everglades landscape models. Landscape Ecology 12:7-18.

Pan, W. K., S. J. Walsh, R. E. Bilsborrow, B. G. Frizzelle, C. M. Erlien, and F. Baquero. 2004. Farm-level models of spatial patterns of land use and land cover dynamics in the Ecuadorian Amazon. Agriculture, Ecosystems and Environment 101:117-134.

Raport, D. J., C. Gaudet, J. R. Karr, J. S. Baron, C. Bohlen, W. Jackson, B. Jones, R. J. Naiman, B. Norton, and M. Pollock. 1998. Evaluating landscape health: integrating societal goals and biophysical process. Journal of Environmental Management 53:1-15.

Remme, W. H., E. H. Everham, L. E. Frelich, M. A. Mortiz, and R. E. Sparks. 1998. Are large, infrequent disturbances qualitatively different from small, frequent disturbances? Ecosystems 1:523-534.

Remmel, T. K., and F. Csillag. 2003. When are two landscape pattern indices significantly different? Journal of Geographical Systems 5:331-351.

Riitters, K. H., R. V. O’Neill, C. T. Hunsaker, J. D. Wickham, D. H. Yankee, S. P. Timmins, K. B. Jones, and B. L. Jackson. 1995. A factor analysis of landscape pattern and structure metrics. Landscape Ecology 10:23-39.

Roger, B., and T.-T. Yu. 2000. The morphology of thrust faulting in the 21 September 1999, Chi-Chi, Taiwan earthquake. Journal of Asian Earth Sciences 18:351-367.

Scatena, F. N., and M. Larsen. 1991. Physical aspects of Hurricane Hugo in Puerto Rico. Biotropica 23:317-323.

Scatena, F. N., and A. E. Lugo. 1995. Geomorphology, disturbance, and the soil and vegetation of two subtropical wet steepland watersheds of Puerto Rico. Geomophology 13:199213

Staus, N. L., J. R. Strittholt, D. A. DellaSala, and R. Robinson. 2002. Rate and pattern of forest disturbance in the Klamath-Siskiyou ecoregion, USA between 1972 and 1992. Landscape Ecology 17:455-470.

Stephens, R. E. 1956. The uprooting of trees: a forest process. Soil Society Proceedings. pp 113-116.

Tinker, D. B., A. C. Resor, G. P. Beauvais, and K. F. Kipfmueller. 1998. Watershed analysis of forest fragmentation by clearcuts and roads in a Wyoming forest. Landscape Ecology 12:149-165.

Tinker, D. B., W. H. Romme, and D. G. Despain. 2003. Historic range of variability in landscape structure in subalpine forests of the Greater Yellowstone Area, USA. Landscape Ecology 18:427-439. 
Turner, M. G., W. L. Kaker, C. J. Peterson, and R. K. Peet. 1998. Factors influencing succession: lessons from large, infrequent natural disturbances. Ecosystems 1:511-523.

Turner, M. G., R. H. Gardner, and R. V. O’Neill. 2001. Landscape ecology in theory and practice-pattern and process. Springer, New York, 401 pp.

Venema, H. D., P. H. Calamai, and P. Fieguth. 2005. Forest structure optimization using evolutionary programming and landscape ecology metrics. European Journal of Operational Research 164:423-439.
Weinstoerffer, J., and P. Girardin. 2000. Assessment of the contribution of land use pattern and intensity to landscape quality: use of a landscape indicator. Ecological Modelling 130:95-109.

White, P. S., and T. A. Pickett. 1985. Natural disturbance and patch dynamics: an introduction. Academic Press, Orlando.

Zhang, L., J. Wu, Y. Zhen, and J. Shu. 2004. A GIS-based gradient analysis of urban landscape patterns of Shanghai metropolitan area, China. Landscape and Urban Planning 69:1-6. 